\section{Pseudo-AIDS, AIDS Panic or AIDS Phobia?}

SIR: Miller et al (Journal, May 1985, 146, 550-551) reported on two men with excessive concern about AIDS: one had a diagnosis of anxiety neurosis, and the other had a diagnosis of depressive illness. The authors argued that this was a new psychiatric condition arising from the AIDS epidemic and coined the term 'pseudo-AIDS'.

Since the publication of this article, similar conditions have been described and called in turn 'AIDSinduced psychogenic state' (O'Brien \& Hassanyeh, Journal, July 1985, 146, 91); 'AIDS phobia' (Jacob et al, Journal, March 1987, 150, 412); or 'AIDS panic' (Windgassen \& Soni, Journal, July 1987, 151, 126-127).

All of these definitions seem to place AIDS in a causative role in creating such conditions. We join O'Brien (Journal, July 1987, 151, 127) in stating that what is important in patients presenting with excessive concern about AIDS, but without the disease, is not AIDS itself, but the underlying psychiatric state.

The common feature of the psychiatric illness, with AIDS concern as a symptom, is hypochondriasis. In hypochondriasis, the illness of which the sufferer has fearful apprehension is usually inherently frightening and often stigmatised by society, classical examples being syphilis and cancer. In addition, the sufferer is often someone who has already been brought into psychological contact with the disease, e.g. by a relative, friend, or even health workers. The fear of AIDS meets all of these criteria (Thompson \& Riccio, 1987). Indeed, Miller (1987) has stated that such patients are similar to those with worries about other venereal diseases.

Fear of AIDS may also be a part of the content of any psychopathology, such as obsessional disorders (Goldmeier, 1987), affective disorders (Lippert, 1986), schizophrenia (Rapport, 1985), or monosymptomatic hypochondriacal delusional states (Lippert, 1986). In such cases of severe psychiatric disorders, the fact that AIDS is the content or object of the psychopathology is of little significance in the diagnosis or treatment of the disorder, which should be carried out in the usual way (Thompson \& Riccio, 1987).

Finally, it can be argued that the term 'AIDS phobia' is misleading. The modern definition of phobia requires the presence not only of irrational fear of a harmless stimulus, but also avoidance of that stimulus. Thus, to be genuinely AIDS phobic, the patient would be required to irrationally avoid AIDS-almost a paradox, except when there is avoidance of AIDS even as a thought or a topic of conversation. The term 'AIDS phobia' is therefore a misnomer, since the patients to whom the term is most applied, i.e. the 'worried well', show little or no tendency to irrationally avoid AIDS.

M. Ruccio

C. THOMPSON

Charing Cross Hospital

Fulham Palace Road

London W6 8RF

\section{References}

Goldmeter, D. (1987) Psychosocial aspects of AIDS. British Journal of Hospital Medicine, March, 232-240.

LIPPERT, G. P. (1986) Excessive concern about AIDS in two bisexual men. Canadian Journal of Psychiatry, 31, 63-66.

MILLER, D. (1987) Predictions of chronic psychosocial disturbance arising from the threat of HIV infection: lessons from heterosexuals, bisexuals, homosexual worried well patients. Poster presentation T.P. 201, III International Conference on AIDS, June 2nd, Washington DC.

RAPAPORT, M. \& BREF, D. L. (1985) 'AIDS and homosexual panic'. American Journal of Psychiatry, 142, 1516.

Thompson, C. \& Riccio, M. (1987) 'AIDS phobia'. British Journal of Hospital Medicine (in press).

\section{Neuroleptic Malignant Syndrome (NMS):} A Misnomer?

SIR: Kellam's review (Journal, June 1987, 150, 752-759) is apt. Perhaps it is time for the nomenclature of so-called NMS to be revised. Besides its possible occurrence before the advent of neuroleptics, it is now well reported that non-neuroleptics are also implicated, e.g. tetrabenazine (Burke et al, 1981), levo-dopa (Henderson \& Wooten, 1981), and dothiepine (Grant, 1984). One case of NMS was attributed to metoclopramide combined with cimetidine (Destee et al, 1981), another was seen in an overdose of benzodiazepines, phenelzine, dothiepin, and alcohol (Ritchie, 1983), and yet another was attributed to amphetamines (Chayasirisobhan et al, 1983). The current restricted nomenclature, using the word neuroleptic, is not an accurate reflection of current facts and predisposes those not familiar with the literature to a sense of false security.

As most cases appear to occur in the context of treatment procedures, "latrogenic malignant syndrome" might be more appropriate, but we would guess that this would prove unpopular, particularly in the context of explaining the condition to patients, their relatives, or possibly their legal advisers.

AsHoK N. Singh

St Brigid's Hospital

JAMES MAGUIRE

Ardee

Co. Louth, Ireland 